\title{
BMJ Open Relationship between socioeconomic status and type 2 diabetes: results from Korea National Health and Nutrition Examination Survey (KNHANES) 2010-2012
}

\author{
Jongnam Hwang, ${ }^{1}$ Changwoo Shon ${ }^{2}$
}

To cite: Hwang J, Shon C. Relationship between socioeconomic status and type 2 diabetes: results from Korea National Health and Nutrition Examination Survey (KNHANES) 2010-2012. BMJ Open 2014;4:e005710. doi:10.1136/bmjopen-2014005710

- Prepublication history for this paper is available online. To view these files please visit the journal online (http://dx.doi.org/10.1136/ bmjopen-2014-005710).

Received 16 May 2014 Revised 14 July 2014 Accepted 1 August 2014

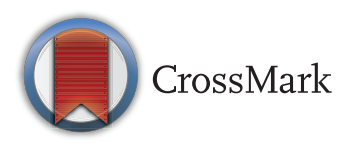

${ }^{1}$ Centre for Research on Inner City Health, St. Michael's Hospital, Toronto, Ontario, Canada

${ }^{2}$ Graduate School of Public Health, Seoul National University, Seoul, Korea

Correspondence to Dr Jongnam Hwang; hwangjo@smh.ca

\section{ABSTRACT}

Objective: To examine the relationship between socioeconomic status (SES) and type 2 diabetes using the Korea National Health and Nutrition Examination Survey (KNHANES) 2010-2012.

Design: A pooled sample cross-sectional study. Setting: A nationally representative population survey data.

Participants: A total of 14330 individuals who participated in the KNHANES 2010-2012 were included in our analysis.

Primary outcome: Prevalence of type 2 diabetes. Results: The relationship between SES and type 2 diabetes was assessed using logistic regression after adjusting for covariates including age, gender, marital status, region, body mass index, physical activity, smoking and high-risk drinking behaviour. After adjustment for covariates, our results indicated that individuals with the lowest income were more likely to have type 2 diabetes than those with the highest income (OR 1.35; $95 \% \mathrm{Cl} 1.08$ to 1.72 ). In addition, lower educational attainment was an independent factor for a higher prevalence of type 2 diabetes in Korea.

Conclusions: These findings suggest the need for developing a health policy to ameliorate socioeconomic inequalities, in particular income and education-related disparities in type 2 diabetes, along with risk factors at the individual level. In addition, future investigations of type 2 diabetes among Koreans should pay more attention to the social determinants of diabetes in order to understand the various causes of the condition.

\section{INTRODUCTION}

Diabetes mellitus is a serious chronic condition that causes lower quality of life and devastates health conditions. ${ }^{1}{ }^{2}$ The estimated prevalence of diabetes in Korea is approximately $7.7 \%$ and it gradually becomes a lifethreatening chronic disease. In comparison with other Organisation for Economic

\section{Strengths and limitations of this study}

This study has affirmed the association between socioeconomic status (SES) and type 2 diabetes in the Korean population.

- Our results show that a low income and low educational attainment are associated with a higher prevalence of type 2 diabetes in Korean adults, consistent with findings in Western populations.

- These findings suggest the need to pay more attention to the social determinants for effective management of type 2 diabetes.

- Causal inferences cannot be made between SES and type 2 diabetes because of the crosssectional design of the study.

Cooperation and Development (OECD) countries, the recent estimated prevalence of diabetes in Korea is higher than the average prevalence of type 2 diabetes among OECD countries, which stands at $6.9 \% .^{3-5}$ The increasing prevalence of diabetes in Korea is a substantial public health issue because it continuously increases the economic and social burden along with a rapid growth in mortality and morbidity. ${ }^{6}{ }^{7}$ Previous studies have suggested that most Koreans diagnosed with diabetes have type 2 diabetes, ${ }^{8}$ and the increasing incidence of type 2 diabetes is closely associated with a rapid growth in the ageing population and $\mathrm{a}$ continuous change to a westernised diet and lifestyle. ${ }^{9}$ In addition to diet and lifestyle factors, there is increasing evidence to suggest a link between socioeconomic status (SES) and the prevalence of type 2 diabetes. ${ }^{10-12}$ For instance, diabetes is more prevalent among materially and socially deprived individuals in developed countries. ${ }^{13}$ It has also been suggested that there is likely to be a higher risk of diabetes in individuals who are obese, physically inactive and have an 
unhealthy diet because these conditions are more common among people with lower SES. ${ }^{14}$ While there is an increasing need for a deeper understanding of the relationship between socioeconomic levels and health outcomes, most existing Korean studies on type 2 diabetes focus on clinical risk factors along with a strong emphasis on health behaviours at the individual level. ${ }^{15-17}$

This paper aims to assess the relationship between SES and the prevalence of diabetes using the Korean National Health and Nutrition Examination Survey (KNHANES), which represents the whole Korean population, with access to a large amount of sociodemographic information.

\section{METHODS}

\section{Study population}

This study used data from KNHANES 2010-2012, a nationally representative population-based survey. The survey was conducted by the Ministry of Health and Welfare and the Korea Centre for Disease Control and Prevention to examine the general health and nutritional status of the Korean population. ${ }^{18}$ It consists of four different components: health interview survey, health behaviour survey, health examination and nutrition survey. The survey information was collected by face-to-face interview following agreement by the individual and a follow-up health examination was performed. The 2010-2012 survey included a total of 25534 individuals. For this analysis, 14330 individuals who responded to sociodemographic questions in both the health interview and health behaviour survey and participated in the health examination were identified.

\section{Prevalence of diabetes}

The survey classified the diabetic conditions of the subjects using three different measures. First, participants were asked whether or not they had a diabetic condition and whether they had ever been diagnosed with diabetes by a physician. Individuals who self-reported having been diagnosed with diabetes by a physician were classified as patients with diabetes. Second, individuals were classified into diabetes, prediabetes and normal based on a fasting glucose level of $>126 \mathrm{mg} / \mathrm{dL}$ in the health examination. Lastly, individuals who self-reported that they were receiving diabetic treatment were classified as having a diabetic condition. Based on these three indicators for diabetes, we recategorised all individuals into diabetic condition and non-diabetic condition. Despite the richness of information from the KNAHES, it did not have any information on the type of diabetes. We therefore assumed that respondents diagnosed with diabetes before the age of 29 years had type 1 diabetes, based on epidemiological trends among the Korean population and previous suggestions on the trend of diabetes in a national survey. ${ }^{8}$ These individuals were excluded from the study. Respondents with any missing or no response values $(n=488)$ were also excluded for an accurate analysis.

\section{Household income and education}

The main indicators of SES in this study were household income and education. In KNHANES, household income quartiles were calculated based on equivalised income (total household income divided by the square root of the numbers of household members). With regard to educational attainment, the participants were asked the level at which their education was completed, which was classified into four educational categories: completion of elementary school, middle school, high school and post-secondary school.

\section{Covariates}

Sociodemographic information such as age, marital status, region and house ownership were included as covariates in the analysis model. Age was reclassified into three categories as follows: young (30-44 years), middle-aged (45-64 years) and older (65 years and over). Marital status was categorised into single and married; the single category included divorced and widowed individuals. In KNHANES, region was originally categorised into 16 regions (Seoul, six metropolitan cities and nine provinces). In this study we recategorised the 16 regions into two regions (Metro Seoul and non-Metro Seoul), as the uneven distribution of the population and resources between Metro Seoul and non-Metro Seoul regions has been previously discussed. ${ }^{19}$ The Metro Seoul region includes Seoul, Incheon metropolitan city and Gyeonggi province, which contain approximately half of the entire Korean population. Housing possession was categorised into owner and non-owner.

In addition, risk factors for diabetes such as increased body mass index (BMI), physical inactivity, smoking and alcohol intake were included. In KNHANES, respondents' height and weight were measured by trained examiners and BMI was calculated and classified into normal/underweight and obese based on the following categories: obese (BMI $\geq 25 \mathrm{~kg} / \mathrm{m}^{2}$ ), normal (BMI 18.5$24.9 \mathrm{~kg} / \mathrm{m}^{2}$ ) and underweight (BMI $\leq 18.5 \mathrm{~kg} / \mathrm{m}^{2}$ ). Participation in physical activity was categorised into moderate and vigorous activities. The participants were also asked about their current smoking and high-risk drinking behaviour. Current smoking behaviour was categorised into currently smoking or not. In the KNHANES survey, high-risk drinking behaviour was defined by gender. Men who drank more than seven cups of alcohol at a single event and more than twice a week and women who drank more than five cups of alcohol at a single event and more than twice a week were classified as individuals with high-risk drinking behaviour. $^{20}$

\section{Statistical analysis}

The relationship between SES and the prevalence of type 2 diabetes was assessed using logistic regression after sequential adjustment of covariates including age, gender, marital status, region, BMI, physical activity, smoking and high-risk drinking behaviour. Model 1 
adjusted for age and income while Model 2 adjusted for age and educational attainment. Model 3 examined the relation with both income and education while adjusting for demographic characteristics. Model 4 adjusted for health behaviours. Because the existing literature suggests that there might be a gender-related difference in the relationship between SES and health outcomes, ${ }^{21} 22$ we also performed a gender-stratified analysis. All analyses were conducted using Stata V.12 and the results are reported as OR and 95\% CIs. Differences were considered significant at $\mathrm{p}<0.05$, and population weight provided by KNHANES was applied to produce estimates representative of the Korean population. ${ }^{18}$

\section{RESULTS}

The characteristics of the individuals with diabetes are shown in table 1. Among an estimated 27378600 respondents aged >30 years, 2765586 individuals $(10.1 \%)$ were identified as having type 2 diabetes. A higher prevalence of diabetes, approximately $53.3 \%$, was observed in respondents who were middle-aged (aged $45-64$ years). The prevalence of diabetes was slightly different in men and women $(55.5 \%$ of men vs $45.5 \%$ of women). Type 2 diabetes was more prevalent in individuals with a lower educational attainment and lower income. Of the patients with diabetes, $72.7 \%$ selfreported owning their own house while $27.3 \%$

Table 1 General characteristics of individuals with type 2 diabetes

\begin{tabular}{|c|c|c|c|c|c|}
\hline \multirow[b]{2}{*}{ Variables } & \multicolumn{2}{|c|}{ Type 2 diabetes } & \multicolumn{2}{|c|}{ Estimated population } & \multirow[b]{2}{*}{ p Value } \\
\hline & $\mathbf{N}$ & $\%$ & $\mathbf{N}$ & $\%$ & \\
\hline & 2765586 & 10.1 & 27378600 & 100 & \\
\hline \multicolumn{6}{|l|}{ Age } \\
\hline Young & 345158 & 12.5 & 10892589 & 39.8 & $<0.001$ \\
\hline Middle-aged & 1474576 & 53.3 & 12122164 & 44.3 & \\
\hline Older & 945851 & 34.2 & 4363847 & 15.9 & \\
\hline \multicolumn{6}{|l|}{ Sex } \\
\hline Men & 1536256 & 55.5 & 13477425 & 49.2 & $<0.001$ \\
\hline Women & 1229330 & 44.5 & 13901175 & 50.8 & \\
\hline \multicolumn{6}{|l|}{ Marital status } \\
\hline Married/partnered & 2145967 & 77.6 & 22242029 & 81.2 & 0.001 \\
\hline Single & 619618 & 22.4 & 5136571 & 18.8 & \\
\hline \multicolumn{6}{|l|}{ Education } \\
\hline Elementary school & 1080057 & 39.1 & 6060731 & 22.1 & $<0.001$ \\
\hline Middle school & 444298 & 16.1 & 3280320 & 12.0 & \\
\hline High school & 820982 & 29.7 & 9505375 & 34.7 & \\
\hline Postgraduate & 420248 & 15.2 & 8532173 & 31.2 & \\
\hline \multicolumn{6}{|l|}{ Income } \\
\hline Q1 & 807879 & 29.2 & 4494685 & 16.4 & $<0.001$ \\
\hline Q2 & 733076 & 26.5 & 7554779 & 27.6 & \\
\hline Q3 & 646824 & 23.4 & 7783332 & 28.4 & \\
\hline Q4 & 577807 & 20.9 & 7545804 & 27.6 & \\
\hline \multicolumn{6}{|l|}{ Region } \\
\hline Non-Metro & 1491763 & 53.9 & 14127908 & 51.6 & 0.148 \\
\hline Metro-Seoul & 1273822 & 46.1 & 13250692 & 48.4 & \\
\hline \multicolumn{6}{|l|}{ House ownership } \\
\hline Yes & 2009688 & 72.7 & 19428320 & 71.0 & 0.242 \\
\hline No & 755897 & 27.3 & 7950280 & 29.0 & \\
\hline \multicolumn{6}{|l|}{ BMI } \\
\hline Normal/underweight & 1438949 & 52.0 & 17878573 & 65.3 & $<0.001$ \\
\hline Obese & 1326636 & 48.0 & 9500026 & 34.7 & \\
\hline \multicolumn{6}{|l|}{ Physical activity } \\
\hline Moderate-Yes & 233861 & 8.5 & 2410729 & 8.8 & 0.688 \\
\hline Moderate-No & 2531725 & 91.5 & 24967871 & 91.2 & \\
\hline Vigorous-Yes & 632725 & 22.9 & 8414982 & 30.7 & $<0.001$ \\
\hline Vigorous-No & 2132860 & 77.1 & 18963618 & 69.3 & \\
\hline \multicolumn{6}{|l|}{ Smoking } \\
\hline Yes & 726243 & 26.3 & 7069758 & 25.8 & 0.745 \\
\hline No & 2039343 & 73.7 & 20308841 & 74.2 & \\
\hline \multicolumn{6}{|l|}{ High-risk drinking } \\
\hline Yes & 269421 & 9.7 & 3053311 & 11.2 & 0.199 \\
\hline No & 2496164 & 90.3 & 24325289 & 88.8 & \\
\hline
\end{tabular}


responded that they did not own a house. More than $52 \%$ of the respondents were in the normal BMI range and 632725 individuals with type 2 diabetes participated in regular vigorous physical activity. In relation to smoking and high-risk drinking behaviours, approximately $26 \%$ of individuals with diabetes were current smokers and more than 9\% had high-risk drinking behaviours.

Table 2 shows the unadjusted and adjusted ORs for the prevalence of diabetes in the Korean population as the results of univariate and multivariate logistic regressions. The lowest household income was associated with a higher risk of diabetes across all different models. In the age-adjusted prevalence of diabetes with income, individuals in the lowest income group were more likely to have type 2 diabetes than those in the highest income group (OR 1.56, 95\% CI 1.25 to 1.94). Although the association between income and type 2 diabetes was reduced with sequential adjustments, the lowest income remained a significant determinant. In the fully adjusted model (model 4), individuals in the lowest income quartile were $35 \%$ more likely to have diabetes compared with those in the highest income quartile. All levels of educational attainment were significantly associated with type 2 diabetes, showing a clear gradient from the lowest to the highest education level. In addition to income and education, sex, age, BMI and participation in vigorous physical activity were associated with a lower prevalence of type 2 diabetes in the Korean population.

In the gender-stratified model (table 3), lower income was associated with a higher prevalence of type 2 diabetes in women while there was no significant relationship between income and type 2 diabetes in men.

\section{DISCUSSION}

Using nationally representative data, we assessed the socioeconomic determinants of type 2 diabetes in the Korean population. Our results show a pattern of higher prevalence towards the lowest household income after adjustment for various sociodemographic factors, suggesting that income is a major determinant of type 2 diabetes among Korean adults. In previous studies income level, a major reflection of economic status, was closely associated with adverse health outcomes including the prevalence of diabetes across studies and across cultures. ${ }^{11} 23-25$ For instance, individuals with a lower income at both individual neighbourhood levels were at higher risk of type 2 diabetes. ${ }^{12} 15$ In line with previous studies, our findings also support the link between income and the prevalence of type 2 diabetes, implying that higher income is an indicator of having better access to goods and services of greater monetary value that leads to an affordable and healthier lifestyle. ${ }^{26}$

It is worth noting that income was not a significant factor associated with type 2 diabetes among Korean men, whereas an inverse relationship between income and the prevalence of type 2 diabetes was observed among Korean women. The current literature has also shown an inverse relationship between chronic conditions such as obesity and diabetes and SES among Korean women, but the reason for the different relationship between income and type 2 diabetes by gender is unclear. A possible explanation is the traditional perception that women are a lower social class than men. This different perception on gender might lead women to be more influenced by income in relation to health, health behaviours and lifestyle. ${ }^{26}$ Further studies are needed to provide a deeper understanding of gender-related differences in the relationship between income and type 2 diabetes.

In addition to income, there was a higher prevalence of type 2 diabetes among individuals with lower educational attainment. Lower educational attainment has been considered as a predictor affecting poor health outcomes and management of chronic disease. ${ }^{27} 28$ For instance, a recent study on SES and the incidence of diabetes suggested that higher educational attainment was associated with a lower risk of diabetes. ${ }^{30}$ Our finding is in line with previous findings that might support an interrelated pathway between education and health. Education level is a marker of the ability to turn information into practical behaviours, with the ultimate goal to prevent or manage chronic diseases. ${ }^{29}$ In this sense, it is plausible that a higher education level supports the improvement of health by increasing health knowledge and motivating healthy behaviours. ${ }^{30} 31$ In addition, higher educational attainment is closely linked to a better physical and social environment. For example, lower educational attainment is in part associated with lower levels of social support and more adverse physical and environmental exposures. ${ }^{32}$ Furthermore, a better education usually implies more opportunities in the labour force market and raises more income, which closely influence healthy behaviours for chronic disease management. ${ }^{33}$ Overall, our finding that type 2 diabetes is more prevalent among individuals with lower educational attainment could be due to the fact that lower educational attainment possibly limits information and resources linking to healthy behaviours and environment exposures. ${ }^{34}$

It is well known that type 2 diabetes is a chronic disease influenced by multiple factors. ${ }^{12}$ Although physiological and genetic factors-which are considered to be major risk factors in the existing literature-play an important role in the prevalence of type 2 diabetes, the role of social and economic conditions needs to be understood..$^{15}$ After adjusting for BMI, physical activity and unhealthy behaviours such as smoking and high-risk drinking, which are the major modifiable lifestyle factors, ${ }^{35}$ our results showed that the effect of income and educational attainment remained quite stable. This finding may imply that type 2 diabetes could be driven by income and education level rather than by individual risk behaviours. In a similar study using a Canadian national survey, the effect of income also persisted after adjustment for various individual risk 
Table 2 Results of univariate and multivariate logistic regression analysis for socioeconomic status and type 2 diabetes in Korea

\begin{tabular}{|c|c|c|c|c|c|c|c|c|c|c|c|c|}
\hline & \multicolumn{3}{|c|}{ Model 1} & \multicolumn{3}{|c|}{ Model 2} & \multicolumn{3}{|c|}{ Model 3} & \multicolumn{3}{|c|}{ Model 4} \\
\hline & OR & $95 \% \mathrm{Cl}$ & p Value & OR & $95 \% \mathrm{Cl}$ & p Value & OR & $95 \% \mathrm{Cl}$ & p Value & OR & $95 \% \mathrm{Cl}$ & p Value \\
\hline \multicolumn{13}{|l|}{ Age } \\
\hline Young (30-44) & 0.14 & 0.11 to 0.18 & $<0.001$ & 0.15 & 0.12 to 0.19 & $<0.001$ & 0.17 & 0.13 to 0.22 & $<0.001$ & 0.16 & 0.12 to 0.21 & $<0.001$ \\
\hline Middle-aged (45-64) & 0.58 & 0.49 to 0.68 & $<0.001$ & 0.55 & 0.47 to 0.63 & $<0.001$ & 0.61 & 0.52 to 0.72 & $<0.001$ & 0.60 & 0.51 to 0.72 & $<0.001$ \\
\hline \multicolumn{13}{|l|}{ Income } \\
\hline Q1 & 1.56 & 1.25 to 1.94 & $<0.001$ & & & & 1.37 & 1.09 to 1.73 & 0.008 & 1.35 & 1.08 to 1.72 & 0.012 \\
\hline Q2 & 1.23 & 1.01 to 1.50 & 0.040 & & & & 1.11 & 0.91 to 1.36 & 0.304 & 1.09 & 0.89 to 1.34 & 0.408 \\
\hline Q3 & 1.18 & 0.95 to 1.45 & 0.129 & & & & 1.11 & 0.89 to 1.37 & 0.346 & 1.09 & 0.88 to 1.35 & 0.456 \\
\hline \multicolumn{13}{|l|}{ Education } \\
\hline Elementary school & & & & 1.59 & 1.25 to 2.03 & $<0.001$ & 1.74 & 1.33 to 2.26 & $<0.001$ & 1.64 & 1.26 to 2.15 & $<0.001$ \\
\hline Middle school & & & & 1.53 & 1.18 to 1.99 & 0.002 & 1.59 & 1.22 to 2.09 & $<0.001$ & 1.51 & 1.15 to 1.98 & 0.003 \\
\hline High school & & & & 1.42 & 1.14 to 1.77 & 0.002 & 1.46 & 1.17 to 1.83 & $<0.001$ & 1.44 & 1.15 to 1.82 & 0.002 \\
\hline \multicolumn{13}{|l|}{ Sex } \\
\hline Female & & & & & & & 0.61 & 0.53 to 0.70 & $<0.001$ & 0.61 & 0.52 to 0.72 & $<0.001$ \\
\hline \multicolumn{13}{|l|}{ Marital status } \\
\hline Single & & & & & & & 0.85 & 0.73 to 1.00 & 0.045 & 0.86 & 0.73 to 1.01 & 0.070 \\
\hline \multicolumn{13}{|l|}{ Region } \\
\hline Metro-Seoul & & & & & & & 1.05 & 0.91 to 1.22 & 0.480 & 1.04 & 0.90 to 1.21 & 0.585 \\
\hline \multicolumn{13}{|l|}{ House ownership } \\
\hline Yes & & & & & & & 0.97 & 0.82 to 1.15 & 0.753 & 0.99 & 0.83 to 1.17 & 0.876 \\
\hline \multicolumn{13}{|l|}{ BMI } \\
\hline Obese & & & & & & & & & & 1.93 & 1.69 to 2.21 & $<0.001$ \\
\hline \multicolumn{13}{|l|}{ Physical activity } \\
\hline Moderate & & & & & & & & & & 0.96 & 0.74 to 1.24 & 0.753 \\
\hline Vigorous & & & & & & & & & & 0.75 & 0.64 to 0.90 & $<0.001$ \\
\hline \multicolumn{13}{|l|}{ Smoking } \\
\hline Yes & & & & & & & & & & 1.14 & 0.95 to 1.36 & 0.154 \\
\hline \multicolumn{13}{|l|}{ High-risk drinking } \\
\hline Yes & & & & & & & & & & 0.97 & 0.74 to 1.28 & 0.854 \\
\hline
\end{tabular}


Table 3 Gender-stratified multivariate logistic regression analysis for socioeconomic status and type 2 diabetes

\begin{tabular}{|c|c|c|c|c|c|c|}
\hline & \multicolumn{3}{|c|}{ Men (estimated N=13 477 425) } & \multicolumn{3}{|c|}{ Women (dstimated N=13 901 175) } \\
\hline & $\overline{\text { OR }}$ & $95 \% \mathrm{Cl}$ & p Value & OR & $95 \% \mathrm{Cl}$ & p Value \\
\hline \multicolumn{7}{|l|}{ Age } \\
\hline Young (30-44) & 0.17 & 0.11 to 0.24 & $<0.001$ & 0.23 & 0.15 to 0.36 & $<0.001$ \\
\hline Middle aged (45-64) & 0.70 & 0.55 to 0.88 & 0.002 & 0.59 & 0.46 to 0.74 & $<0.001$ \\
\hline \multicolumn{7}{|l|}{ Income } \\
\hline Q1 & 1.22 & 0.87 to 1.72 & 0.244 & 1.68 & 1.18 to 2.38 & 0.006 \\
\hline Q2 & 0.88 & 0.66 to 1.16 & 0.351 & 1.55 & 1.13 to 2.12 & 0.004 \\
\hline Q3 & 0.97 & 0.75 to 1.27 & 0.850 & 1.31 & 0.92 to 1.88 & 0.133 \\
\hline \multicolumn{7}{|l|}{ Education } \\
\hline Elementary school & 1.27 & 0.92 to 1.77 & 0.152 & 2.41 & 1.48 to 3.92 & $<0.001$ \\
\hline Middle school & 1.52 & 1.11 to 2.10 & 0.010 & 1.84 & 1.10 to 3.07 & 0.020 \\
\hline High school & 1.43 & 1.10 to 1.85 & 0.008 & 1.68 & 1.06 to 2.66 & 0.028 \\
\hline \multicolumn{7}{|l|}{ Marital status } \\
\hline Single & 1.18 & 0.84 to 1.65 & 0.334 & 0.76 & 0.61 to 0.93 & 0.009 \\
\hline \multicolumn{7}{|l|}{ Region } \\
\hline Metro-Seoul & 1.04 & 0.85 to 1.29 & 0.686 & 1.08 & 0.88 to 1.32 & 0.468 \\
\hline \multicolumn{7}{|l|}{ House ownership } \\
\hline Yes & 1.03 & 0.80 to 1.31 & 0.846 & 0.96 & 0.76 to 1.21 & 0.724 \\
\hline \multicolumn{7}{|l|}{$\mathrm{BMI}$} \\
\hline Obese & 1.45 & 1.19 to 1.78 & $<0.001$ & 2.58 & 2.16 to 3.09 & $<0.001$ \\
\hline \multicolumn{7}{|l|}{ Physical activity } \\
\hline Moderate & 1.10 & 0.80 to 1.52 & 0.556 & 0.76 & 0.54 to 1.07 & 0.128 \\
\hline Vigorous & 0.73 & 0.59 to 0.90 & 0.004 & 0.80 & 0.60 to 1.07 & 0.118 \\
\hline \multicolumn{7}{|l|}{ Smoking } \\
\hline Yes & 1.16 & 0.95 to 1.41 & 0.151 & 0.96 & 0.62 to 1.47 & 0.655 \\
\hline \multicolumn{7}{|l|}{ High-risk drinking } \\
\hline Yes & 1.00 & 0.74 to 1.33 & 0.979 & 0.83 & 0.37 to 1.87 & 0.836 \\
\hline
\end{tabular}

factors, suggesting that individual risk behaviours do not extensively explain the prevalence of diabetes as health and health behaviours are continuously shaped by socioeconomic conditions. ${ }^{15}$ This consistent finding may enable us to conclude that an increasing awareness of social determinants is useful for understanding the potential contributions for the incidence and management of type 2 diabetes. $^{12}$

Due to the nature of the complexity of SES, ${ }^{31}$ it is not clear which dimension of SES mainly shapes type 2 diabetes. ${ }^{15}$ The existing literature shows mixed findings on the role of income and education on the prevalence of type 2 diabetes. One study examining the association between diabetes and SES (with a combination of household income and educational attainment) indicated that individuals who had completed college education and had a higher income were approximately $30 \%$ less likely to have diabetes than those of lower SES. ${ }^{10}$ Other studies suggest that education plays a stronger role in type 2 diabetes, while another study suggested that the gross effect of education disappeared after adjustment for sociodemographic factors and income in the analytical model. ${ }^{36} 37$ Further studies are needed to understand the structural link between income/education and type 2 diabetes in order to provide more evidence on the effective management of type 2 diabetes among the Korean population.
The higher prevalence of type 2 diabetes among lower income and education groups is a particular problem because it can aggravate the cycle of inequality. ${ }^{38}$ First, increasing the financial burden of healthcare cost further deteriorates the personal economic condition. ${ }^{39}$ Even though the Korean National Health Insurance provides universal healthcare coverage for healthcare services, individuals still share high levels of out-of-pocket payments for physician services and prescriptions. ${ }^{40}$ It is possible that disadvantaged individuals with diabetes encounter an excessive burden of healthcare cost as they already have financial difficulties. Also, it is possible that disadvantaged individuals have limited access to the necessary resources for the management of diabetes. ${ }^{39}$ This includes adequate housing, healthier food and essential healthcare services. ${ }^{12}$ Thus, diabetes decreases an individual's productivity at work or limits their participation in the labour force and educational opportunities. ${ }^{41}$ These limited opportunities have a greater effect on individuals with lower income and education, which can ultimately lead to further material and social deprivation. ${ }^{3941}$ In order to prevent exacerbating the causes of the causes, improving the prevention and management of diabetes with the lens of social determinants of health requires a population-based and multilevel approach. ${ }^{39} 42$

To our knowledge, there is little in the Korean literature on the relationship between SES and the 
prevalence of type 2 diabetes at the population level. Our study contributes to the literature, highlighting the role of income and education on the prevalence of type 2 diabetes. While numerous studies have analysed the risk factors for type 2 diabetes, our study is an original contribution to the literature because we have investigated the importance of socioeconomic determinants in relation to the prevalence of type 2 diabetes among the Korean population.

Despite several meaningful findings of our study, there are a number of limitations. First, the cross-sectional design of our study limits assumptions of causality, at least with respect to the association of social determinants (mainly income) with type 2 diabetes. Also, we cannot exclude reverse causality in the observed findings - that is, pre-existing diagnosed diabetes may cause reduced income due to loss of job, for instance, hence causing reduced income. In addition, we were unable to distinguish between type 1 and type 2 diabetes. However, our exclusion of adults aged $<30$ years probably minimised new-onset type 1 diabetes, ${ }^{8}$ and therefore our findings are most likely applicable to patients with type 2 diabetes. Finally, the KNHANES is a self-reported survey and therefore prone to measurement error and recall bias as well as to reporting heterogeneity in self-reported health. For example, individuals with less educational attainment are less likely to recall their sociodemographic and health information. ${ }^{25} 43$ Also, patients with non-severe symptoms of diabetes were not able to identify their diabetic condition. For accurate analysis to overcome these recognised limitations, we used the variable of diabetic condition diagnosed by a physician. ${ }^{5}$ Further studies should consider the use of administrative or registry-based data.

\section{CONCLUSION}

The findings of our study show that SES, particularly income and educational attainment, are important factors in a higher prevalence of type 2 diabetes, regardless of various sociodemographic factors that may confound or mediate these associations. The growing prevalence of type 2 diabetes and widening of the gap between better off and worse off individuals become substantial issues in Korea. Strategies for diabetes prevention and management should therefore focus on social determinants in addition to risk factors at the individual level. Our findings suggest that, in future investigations of the cause of type 2 diabetes among Koreans, attention should be paid to social determinants of health such as income and education.

Acknowledgements The authors are grateful to Dr Calypes Agbosangaya at the University of Alberta, Canada for thoughtful comments and English language editing on an earlier version of this article.

Contributors $\mathrm{JH}$ and CS contributed to the study concept, design, interpretation of the data and preparation of the manuscript. JH conducted the statistical analysis.
Funding This research received no specific grant from any funding agency in the public, commercial or not-for-profit sectors.

\section{Competing interests None.}

Provenance and peer review Not commissioned; externally peer reviewed.

Data sharing statement No additional data are available.

Open Access This is an Open Access article distributed in accordance with the Creative Commons Attribution Non Commercial (CC BY-NC 4.0) license, which permits others to distribute, remix, adapt, build upon this work noncommercially, and license their derivative works on different terms, provided the original work is properly cited and the use is non-commercial. See: http:// creativecommons.org/licenses/by-nc/4.0/

\section{REFERENCES}

1. Deshpande AD, Harris-Hayes M, Schootman M. Epidemiology of diabetes and diabetes-related complications. Physical Therapy 2008;88:1254-64.

2. Schäfer I, Pawels M, Küver C, et al. Strategies for improving participation in diabetes education. A qualitative study. PLOS One 2014;9:e95035.

3. OECD. Health at a glance 2013: OECD indicators. Organisation for Economic Co-operation and Development (OECD) Publishing, 2013.

4. Park IB, Kim J, Kim DJ, et al. Diabetes epidemics in Korea: reappraise nationwide survey of diabetes "diabetes in Korea 2007". Diabetes Metab J 2013;37:233-9.

5. Hwang J, Johnson JA. Relationship between duration of type 2 diabetes and self-reported participation in diabetes education in Korea. Asia Pac J Public Health Published Online First: 11 April 2012. doi: $10.1177 / 1010539512440592$

6. Kim SG, Choi DS. The present state of diabetes mellitus in Korea. $J$ Korean Med Assoc 2008:51:791-8.

7. Choi YJ, Kim HC, Kim HM, et al. Prevalence and management of diabetes in Korean adults: Korea National Health and Nutrition Examination Surveys 1998-2005. Diabetes Care 2009;32:2016-20.

8. Rhee B. Epidemiological characteristics of diabetes mellitus among Korean population. J Korean Diabetes Assoc 2003;27:173-9.

9. Kim SM, Lee JS, Lee J, et al. Prevalence of diabetes and impaired fasting glucose in Korea: Korean National Health and Nutrition Survey 2001. Diabetes Care 2006;29:226-31.

10. Min H, Chang J, Balkrishnan R. Sociodemographic risk factors of diabetes and hypertension prevalence in republic of Korea. Int $J$ Hypertens 2010;2010. pii: 410794.

11. Rabi DM, Edwards AL, Southern DA, et al. Association of socio-economic status with diabetes prevalence and utilization of diabetes care services. BMC Health Serv Res 2006:6:124.

12. Raphael D, Anstice S, Raine K, et al. The social determinants of the incidence and management of type 2 diabetes mellitus: are we prepared to rethink our questions and redirect our research activities? Leadersh Health Ser 2003;16:10-20.

13. Brown AF, Ettner SL, Piette J, et al. Socioeconomic position and health among persons with diabetes mellitus: a conceptual framework and review of the literature. Epidemiol Rev 2004;26:63-77.

14. Demakakos $P$, Marmot M, Steptoe A. Socioeconomic position and the incidence of type 2 diabetes: the ELSA study. Eur J Epidemiol 2012;27:367-78.

15. Dinca-Panaitescu S, Dinca-Panaitescu M, Bryant T, et al. Diabetes prevalence and income: results of the Canadian Community Health Survey. Health Policy 2011;99:116-23.

16. Cho NH. The epidemiology of diabetes in Korea: from the economics to genetics. Korean Diabetes J 2010;34:10-15.

17. Khang $\mathrm{YH}, \mathrm{Kim} \mathrm{HR}$. Explaining socioeconomic inequality in mortality among South Koreans: an examination of multiple pathways in a nationally representative longitudinal study. Int $J$ Epidemiol 2005;34:630-7.

18. Kweon S, Kim Y, Jang M-j, et al. Data resource profile: The Korea National Health and Nutrition Examination Survey (KNHANES). Int $J$ Epidemiol 2014;43:69-77.

19. Lee K. Distribution characteristics of the medical services in Korea $J$ Korean Geogr Soc 2005;40:242-511.

20. KCDC. The Fifth Korea National Health and Nutrition Examination Survey Data User Guide. Korea Centers for Disease Control and Prevention (KCDC), 2012.

21. Chun $\mathrm{H}$, Khang $\mathrm{Y}-\mathrm{H}$, Kim $\mathrm{I}-\mathrm{H}$, et al. Explaining gender differences in ill-health in South Korea: the roles of socio-structural, psychosocial, and behavioral factors. Soc Sci Med 2008;67:988-1001. 
22. Kim H-J, Ruger J. Socioeconomic disparities in behavioral risk factors and health outcomes by gender in the Republic of Korea. BMC Public Health 2010;10:195.

23. Krishnan S, Cozier YC, Rosenberg L, et al. Socioeconomic status and incidence of type 2 diabetes: results from the Black Women's Health Study. Am J Epidemiol 2010;171:564-70.

24. Lysy Z, Booth GL, Shah BR, et al. The impact of income on the incidence of diabetes: a population-based study. Diabetes Res Clin Pract 2013;99:372-9.

25. Espelt A, Borrell C, Roskam AJ, et al. Socioeconomic inequalities in diabetes mellitus across Europe at the beginning of the 21 st century. Diabetologia 2008;51:1971-9.

26. Tang M, Chen Y, Krewski D. Gender-related differences in the association between socioeconomic status and self-reported diabetes. Int J Epidemiol 2003;32:381-5.

27. Choi Al, Weekley CC, Chen S-C, et al. Association of educational attainment with chronic disease and mortality: the Kidney Early Evaluation Program (KEEP). Am J Kidney Dis 2011;58:228-34.

28. Adler NE, Boyce T, Chesney MA, et al. Socioeconomic status and health. The challenge of the gradient. Am Psychol 1994;49:15-24.

29. Geyer S, Hemström Ö, Peter R, et al. Education, income, and occupational class cannot be used interchangeably in social epidemiology. Empirical evidence against a common practice. $J$ Epidemiol Community Health 2006;60:804-10.

30. Lee TC, Glynn RJ, Peña JM, et al. Socioeconomic status and incident type 2 diabetes mellitus: data from the Women's Health Study. PLoS One 2011;6:e27670.

31. Braveman P, Egerter S, Williams DR. The social determinants of health: coming of age. Annu Rev Public Health 2011;32:381-98.

32. Silles MA. The causal effect of education on health: evidence from the United Kingdom. Econ Educ Rev 2009;28:122-8.
33. Adler NE, Newman K. Socioeconomic disparities in health: pathways and policies. Health Aff 2002;21:60-76.

34. Suhrcke M, de Paz Nieves C. The impact of health and health behaviours on educational outcomes in high-income countries: a review of the evidence. Copenhagen: WHO Regional Office for Europe, 2011.

35. Rimm EB, Chan J, Stampfer MJ, et al. Prospective study of cigarette smoking, alcohol use, and the risk of diabetes in men. BMJ 1995;310:555-9.

36. Braveman PA, Cubbin C, Egerter S, et al. Socioeconomic status in health research: one size does not fit all. JAMA 2005;294:2879-88.

37. Winkleby MA, Jatulis DE, Frank E, et al. Socioeconomic status and health: how education, income, and occupation contribute to risk factors for cardiovascular disease. Am J Public Health 1992;82:816-20.

38. Marmot M. Social determinants of health inequalities. Lancet 365:1099-104.

39. Hill J, Nielsen M, Fox MH. Understanding the social factors that contribute to diabetes: a means to informing health care and social policies for the chronically ill. Perm J 2013;17:67-72.

40. Heo J-H, Cho Y-T, Kwon S-M. The effects of socioeconomic deprivations on health. Korean J Sociol 2010;44:93-120.

41. Kraut A, Walld R, Tate R, et al. Impact of diabetes on employment and income in Manitoba, Canada. Diabetes Care 2001;24:64-8.

42. Glasgow R, Wagner E, Kaplan R, et al. If diabetes is a public health problem, why not treat it as one? A population-based approach to chronic illness. Ann Behav Med 1999;21:159-70.

43. Mackenbach JP, Looman CW, van der Meer JB. Differences in the misreporting of chronic conditions by level of education: the effect on inequalities in prevalence rates. Am J Public Health 1996;86:706-11. 